Zaremba A. (2015). The January seasonality and the performance of country-level value and momentum strategies. Copernican Journal of Finance \& Accounting, 4(2), 195-209. http://dx.doi. org/10.12775/CJFA.2015.024

\author{
AdAm Zaremba* \\ Poznań University of Economics
}

\title{
THE JANUARY SEASONALITY AND THE PERFORMANCE OF COUNTRY-LEVEL VALUE AND MOMENTUM STRATEGIES
}

Keywords: January effect, turn-of-the-year effect, value, momentum, country-level anomalies, international investments, cross section of stock returns, asset pricing.

J E L Classification: G11, G12, G14, G15.

Abstract: The study examines the turn-of-the-year effect in the country-level value and momentum strategies. We re-examine eight distinct value and momentum strategies within 78 markets in the 1995-2015 period and we test their performance for the seasonal patterns. We find that during the last 20 years the value strategies performed particularly well in January and poor in December. On the contrary, the momentum strategies had high returns in December and low in January. These observations are consistent with the explanations of the January seasonality related to the tax loss selling and window dressing effects.

Translated by Adam Zaremba

\section{IIINTRODUCTION}

The primary aim of this study is to examine the influence of the turn-of -theyear effect on the performance of the country-level anomalies related to val-

Date of submission: June 25, 2015; date of acceptance: October 8, 2015.

* Contact information: adam.zaremba@ue.poznan.pl, Poznań University of Economics, Al. Niepodległości 10, 61-875 Poznań, Poland, phone: +48 618543828. 
ue and momentum effects. The turn-of-the-year effect, or in other words the January effect, is a tendency of stocks to perform particularly well in January. Since its discovery almost 40 years ago (Rozeff and Kinney 1976), it has been explained in many ways, but it appears that only two hypotheses hold up to serious scrutiny. The tax loss selling story assumes that at the end of the year investors sell stocks that have "lost money" to capture the capital loss, resulting in the low or negative returns, and then buy them back in January, driving the prices up (Chen and Singal 2004). The second rationale - the window dressing hypothesis - relates the turn-of-the-year phenomenon to the behaviour of institutional investors, who "clean" their balance sheets before the end of December. This is the time when the detailed portfolio composition is reported to investors (Haugen and Lakonishok 1988, Lakonishok et al. 1991). Thus, they sell the risky and neglected stocks in December and buy them back at the beginning of the year.

Both hypotheses have vivid implications for the two most popular and best documented cross-sectional investment strategies: value and momentum investing. The value effect is related to the fact that stocks with high (low) fundamentals relative to the market price outperform stocks with low (high) fundamentals to the price ratio. The momentum anomaly is a phenomenon that the stocks that performed well (poor) over recent 3-12 months usually continue to outperform (underperform). Both anomalies are proven to be robust and reliable sources of return and both of them have been documented across all the major asset classes (Asness et al. 2013). The both explanations of the January effect, i.e. tax loss selling and window dressing hypotheses, suggest that investors should sell risk and neglected stocks, perhaps with poor past longterm performance, so the stocks that bear all the characteristics of the value stocks, in December, and then buy them back in January. Thus, the value strategies should underperform in December and perform particularly well in the beginning of the year. Conversely, considering the momentum effect, investors should stick to the winning companies at the end of the year, and then switch to the value stocks in the January. In other words, the momentum anomaly should deliver high returns in the last month of the year, but also rather poor performance in January. The empirical evidence seems to be generally consistent with these hypotheses. Davis (1994) and Loughram (1997) find that the stocklevel value premium is particularly high in January, while Yao (2012) and NovyMarx (2012) indicate, that the momentum returns are highest in December and lowest in January. 
In this study, we bring the research on the seasonality in value and momentum returns into a new global dimension. A few studies show, that the value and momentum effects could be applied not only to the stocks, but also entire country equity markets. In other words, there is substantial evidence that countries with the high fundamentals relative to the market capitalization outperform countries with the low fundamentals relative to stock market capitalization (Asness et al. 1997, Kim 2012, Zaremba 2015a). Analogously, the stock markets that outperformed in the past 12 months tend to perform well in the future (Bhojraj and Swaminathan 2006, Balvers and Wu 2006). But does the turn-of-the-year seasonality exert similar impact on the country-level value and momentum effects as on the stock-level anomalies? The goal of this study is to answer this question, that has not been discussed in the global academic literature yet.

Presumably, the same arguments stemming from the tax selling and window dressing explanations that are used for the stock-level effects, could be also applied for the country-level effects. On the one hand, investment managers might reduce the exposure to risky countries, that would not be well perceived by investors reviewing the funds' financial statements. On the other hand, the individual investors could sell the funds exposed to the "loser countries" to capture the capital loss. The impact of both effects would be potentially unwound in January.

Summing up, we suppose that the turn-of-the-year effect could be applied to the country-level value and momentum strategies, analogous as to the stocklevel parallels. We expect the value strategies to outperform in January relative to December, and the momentum portfolios to have higher returns in December than in January. Thus, our null hypothesis is:

$H_{0}$ : the country-level value and momentum strategies have equal returns in December and January,

with the alternative hypothesis assuming the contrary:

$H_{1}$ : the country-level value and momentum strategies do not have equal returns in December and January.

The motivation for this study is twofold. First, we want to provide fresh outof-sample evidence on the turn-of-the-year effect. But second, and more importantly, the goal is to offer new tools for international investors. The stock-level 
market participants have at their disposal substantial economic literature devoted to cross-sectional return patterns. Jacobs (2015) recently reviewed 100 stock-market anomalies from tier-one academic journals. In comparison with this "factor zoo", the tools available for country-level investors, who base their strategies on exchange traded funds (ETFs) or stock index futures, are rather modest. Furthermore, the papers containing meta-analysis, that investigate some commonalities across the country-level anomalies, are almost non-existent. This shortage of useful tools is particularly striking given the fact that the last years have seen unprecedented growth of country-level investment vehicles: e.g. futures, index funds and ETFs. These structural changes call for new tools for global investors.

This study investigates the performance of eight distinct value and momentum anomalies within a sample of 78 country equity markets in the period between 1995-2015. We first re-examine the performance of the country-level strategies, and then test the time series of returns for the potential turn-of-theyear effect.

The principal findings of the paper can be summarized as follows. During the last 20 years the value strategies performed particularly well in January and underperformed in December. On the contrary, the momentum strategies had the substantially high returns in December and low in January. Nonetheless, the observations lack sufficient statistical significance to formally reject the hypothesis of the study.

The remainder of this article has the following structure: the next section covers data and research methods, which is followed by a presentation and discussion of findings. The last section concludes the paper and indicates the areas for further research.

\section{DATA AND METHODS}

The primary aim of this study is to test seasonal patterns around the turn of the year in the country-level value and momentum anomalies. Thus, the empirical analysis could be divided into two subsections: (1) we select and reexamine the appropriate cross-country anomalies, (2) we test them for the effects related to January and December. This section first describes the data sources, the procedures employed in the construction of anomalies-based portfolios, and asset-pricing models employed to examine them. Subsequently, the methods utilized to investigate the seasonal patterns are discussed. 
The calculations in this study are based on returns on MSCI international stock market indices from 78 countries, including both existing and discontinued indices (e.g. MSCI Venezuela) ${ }^{1}$. We use monthly time series from the period June 1995 - May 2015 sourced from the Bloomberg database. Returns are calculated on the basis of capitalization-weighted total return indices. We utilize both gross return and net return indices, i.e. unadjusted and adjusted for taxes on dividends, to provide the robustness of results and express the standpoint of both institutional and individual investors. A stock market is included in the sample in month $t$, when it is possible to compute its returns in month $t$ and its metric necessary to sort the countries for the need of portfolios formation at the end of month $t-1$. Data are collected in local currencies and subsequently denominated in US\$ to obtain polled international results. To ensure consistency with the US\$ approach, excess returns were computed over returns on the Bloomberg generic US 1-month T-Bill.

We first examine the performance of long/short zero-portfolios formed based on two groups of anomalies. The first group is related to the concept of value investing, i.e. the phenomenon that stocks with high fundamentals relative to price outperform stocks with low fundamentals. This effect has been so far documented with the use of many various valuation ratios, e.g. bookto-market ratio (Rosenberg et al. 1985), earnings-to-price-ratio (Basu 1983), or dividend yield (Litzenberger and Ramaswamy 1979). A number of authors documented that these anomalies has their country-level parallels, so, in other words, "value countries" outperform "growth countries" (Asness et al. 1997, Kim 2012, Zaremba 2015a). In this papers we base the tested portfolios only on the four metrics that are found to me the most reliable in the study of Zaremba (2015b): earnings-to-price ratio (EP), EBITDA-to-EV ratio (EBEV), EBITDAto-price ratio (EBP) and sales-to-EV ratio (SEV). In each case, we calculate the

${ }^{1}$ Argentina, Australia, Austria, Bahrain, Bangladesh, Belgium, Brazil, Bulgaria, Canada, Chile, China, Colombia, Croatia, Cyprus, Czech Republic, Denmark, Egypt, Estonia, Finland, France, Germany, Greece, Hong Kong, Hungary, Iceland, India, Indonesia, Ireland, Israel, Italy, Japan, Jordan, Kazakhstan, Kenya, Kuwait, Latvia, Lebanon, Lithuania, Luxemburg, Malaysia, Malta, Mexico, Morocco, Mauritius, Netherlands, New Zealand, Nigeria, Norway, Oman, Pakistan, Peru, Philippines, Poland, Portugal, Qatar, Romania, Russia, Serbia, Saudi Arabia, Singapore, Slovenia, South Africa, South Korea, Spain, Sri Lanka, Sweden, Switzerland, Taiwan, Thailand, Trinidad and Tobago, Tunisia, Turkey, Ukraine, United Arab Emirates, United Kingdom, USA, Venezuela, Vietnam. If an MSCI index is not available for some country, the second choice is the Dow Jones index, and the third choice is STOXX. 
total accounting measure aggregated over four prior quarters and divide it by the current total stock market capitalization or EV. The accounting measures for the indices are the summed values for all the constituent companies, w8ed according to the methodology of a given index. Furthermore, all the ratios are lagged three months in order to avoid look-ahead bias.

The second group of anomalies is related to momentum, which is found in country equity indices by for example Asness et al. (1997), Bhojraj and Swaminathan (2006), and Balvers and $\mathrm{Wu}$ (2006). We examine two separate version of the anomaly. First, we examine the standard long-term momentum (LtMom), where portfolios are formed on the basis of 12-month past performance with the most recent month skipped (Fama and French 2008). Second, we investigate the intermediate momentum (IntMom) suggested by Novy-Marx (2012). We do not examine the classical short-term momentum originating from Jegadeesh and Titman (1993), that was based on 6-month past performance. The reason is that Novy-Marx (2012) suggest that it's source lies predominantly in the postearnings announcement drift, which is not present at the country-level. Furthermore, Zaremba (2015b) and Zaremba and Konieczka (2015) finds no significant evidence for the short-term momentum within country equity indices.

For all the above-described strategies, the zero-portfolios are formed in a uniform way. First, all the stock market indices are sorted on the metrics related to the anomalies at the end of each month $t-1$. Next, we determine the $20^{\text {th }}$ and $80^{\text {th }}$ percentiles as breakpoints, and thus form three subgroups. Subsequently, the returns on indices in the top and the bottom subgroup are equally w8ed to form portfolios. Finally, we calculate returns on the differential portfolio - in other words zero-portfolios - which are long/short portfolios: $100 \%$ long in the quintile of markets with the highest metric, and $100 \%$ short in the quintile of markets with the lowest metric.

Beside the strategies based on single metrics, we calculate also returns on composite strategies, that are equal weighted portfolios of all the strategies within the two groups: value and momentum. Thus, we have a composite value strategy, that is based on average performance of the four single-variable value strategies, and a composite momentum strategy, that basically averages returns on long-term and intermediate momentum.

Following Zaremba and Konieczka (2015), the performance of the portfolios is examined with two distinct asset pricing model. The first is the countrylevel CAPM model (Sharpe, 1964), where the global market portfolio includes all the country equity indices. The return on the market portfolio in this case is 
calculated either in the gross or net approach, consistently with the returns on anomaly-based portfolios. The other model is the standard four-factor model by Carhart (1997) based the US stock-level data ${ }^{2}$. We base all the formal statistical inferences on log-returns and present the outcomes accordingly.

Considering the impact of seasonality on the returns on value and momentum anomalies, we are particularly interested whether the performance in January is significantly better than in December. We use two separate methods to verify this hypothesis. Initially, we simply calculate the mean returns in the two above-mentioned months and tests whether the difference is significantly different from 0 . In this test, for the sake of simplicity, we assume that the January and December log-returns are independent and normally distributed. ${ }^{3}$ Next, using the OLS method, we estimate the parameters of the following regression equation:

$$
r_{t}^{i}=\alpha^{i}+\beta^{i} \times J A N_{t}+\gamma^{i} \times D E C_{t}+\varepsilon_{t}^{i},
$$

where $r_{t}^{i}$ is the return on $i$-th strategy in month $t, J A N_{t}$ and $D E C_{t}$ are dummy variables equal 1 when month $t$ is January and December, respectively, or 0 otherwise, $\varepsilon_{t}^{i}$ is the standard error, and $\alpha^{i}, \beta^{i}$ and $\gamma^{i}$ are the regression parameters. Finally, for each strategy we test the null hypothesis that $\beta^{i}$ is equal $\gamma^{i}$, with the alternative hypothesis assuming the contrary. To examine whether the difference in coefficients significantly departs from 0 , we follow the approach suggested by Paternoster et al. (1998).

\section{RESULTS AND DiscusSION}

Table 1 reports the performance of the examined value and momentum strategies. Almost all the examined strategies are characterized returns that are positive and significantly different from 0 , even after the CAPM and four-factor models are applied. Basically, adjusting for cross-sectionally varying taxes on dividends do not change the picture and most of the strategies remain ro-

2 The stock level data come from Andrea Frazzini's data library accessed on 25 June, 2015: http://www.econ.yale.edu/ af227/data_library.htm.

${ }^{3}$ We are aware that these assumptions may be regarded as an oversimplification, but, as it is shown later in the paper, it is sufficient for this paper and any more sophisticated method would not substantially change the outcomes. 
bust and reliable sources of returns. Analogously, the performance of the composite strategies is also characterized by positive and abnormal returns, that withstand the adjustment for the global and local risk factors. The Sharpe ratio on the composite strategies in the gross and net approaches, respectively, are equal 0.86 and 0.75 for the value anomalies, and 0.58 and 0.51 for the momentum. The outperformance of the value strategies stems mainly from their lover volatility.

Two of the examined strategies may appear a bit controversial from the standpoint of their robustness. First, the zero-portfolios from sorts on earnings-to-price ratios have are positive returns that significantly differ from 0 only in the net approach. Furthermore, the intercepts from asset pricing models are not significant either. Nonetheless, Zaremba and Konieczka (2015), who examine this strategy also for alternative weighting scheme, find it one of the most reliable and robust strategies, so we qualify it for further investigations. Analogously, the soft spot of the long-term momentum strategy seems to be adjustment for taxes; the abnormal returns in this approach are no longer significant. Nonetheless, numerous studies, e.g. Asness et al. (2013), document that the momentum effect is so pervasive, so we also include it in the further part of the study.

Table 1. Performance of the zero-portfolios based on the examined anomalies

\begin{tabular}{|c|c|c|c|c|c|c|c|c|c|c|}
\hline & Mean & St. dev. & SR & $\alpha_{\text {CAPM }}$ & $\alpha_{4 \mathrm{~F}}$ & Mean & St. dev. & SR & $\alpha_{\text {CAPM }}$ & $\alpha_{4 F}$ \\
\hline & \multicolumn{5}{|c|}{ Gross returns approach } & \multicolumn{5}{|c|}{ Net returns approach } \\
\hline & \multicolumn{10}{|c|}{ Value } \\
\hline \multirow[t]{2}{*}{ EP } & 0.32 & 3.99 & 0.28 & 0.29 & 0.24 & $0.47 * *$ & 3.60 & 0.45 & 0.41 & 0.38 \\
\hline & (1.47) & & & (1.16) & $(0.97)$ & $(2.00)$ & & & (1.60) & (1.51) \\
\hline \multirow[t]{2}{*}{ EBEV } & $0.96 * * *$ & 4.25 & 0.79 & $0.95 * * *$ & $0.88 * * *$ & $0.64^{* *}$ & 3.94 & 0.57 & $0.57 * *$ & $0.53^{* *}$ \\
\hline & (3.54) & & & (3.51) & (3.26) & $(2.27)$ & & & (2.24) & $(2.04)$ \\
\hline \multirow[t]{2}{*}{ EBP } & $0.84 * * *$ & 4.08 & 0.71 & $0.80 * * *$ & $0.70 * * *$ & $0.73^{* *}$ & 4.21 & 0.60 & $0.64 * *$ & $0.56^{* *}$ \\
\hline & $(3.00)$ & & & (3.12) & $(2.84)$ & $(2.20)$ & & & $(2.23)$ & $(2.05)$ \\
\hline \multirow[t]{2}{*}{ SEV } & $0.69 * * *$ & 3.90 & 0.61 & $0.68^{* * *}$ & $0.64 * *$ & $0.58^{* * *}$ & 3.07 & 0.65 & $0.52^{* *}$ & $0.47^{* *}$ \\
\hline & (3.09) & & & (2.64) & (2.56) & (3.15) & & & (2.42) & $(2.25)$ \\
\hline \multirow[t]{2}{*}{ CompVal } & $0.74 * * *$ & 2.99 & 0.86 & $0.72 * * *$ & $0.68 * * *$ & $0.63 * * *$ & 2.93 & 0.75 & $0.55^{* * *}$ & $0.50 * * *$ \\
\hline & (3.83) & & & (3.34) & (2.98) & (3.00) & & & (2.89) & (2.65) \\
\hline
\end{tabular}




\begin{tabular}{|c|c|c|c|c|c|c|c|c|c|c|}
\hline & Mean & St. dev. & SR & $\alpha_{\text {CAPM }}$ & $\alpha_{4 \mathrm{~F}}$ & Mean & St. dev. & SR & $\alpha_{\mathrm{CAPM}}$ & $\alpha_{4 \mathrm{~F}}$ \\
\hline & \multicolumn{5}{|c|}{ Gross returns approach } & \multicolumn{5}{|c|}{ Net returns approach } \\
\hline & \multicolumn{10}{|c|}{ Momentum } \\
\hline \multirow[t]{2}{*}{ LtMom } & $0.64^{*}$ & 4.71 & 0.47 & $0.68^{* *}$ & $0.52 *$ & 0.44 & 4.42 & 0.34 & 0.49 & 0.34 \\
\hline & (1.96) & & & (2.18) & $(1.82)$ & $(1.40)$ & & & (1.55) & (1.21) \\
\hline \multirow[t]{2}{*}{ IntMom } & $0.74 * *$ & 4.38 & 0.58 & $0.77^{* * *}$ & $0.63 * *$ & $0.72 * *$ & 4.42 & 0.57 & $0.77^{* *}$ & $0.64 * *$ \\
\hline & $(2.52)$ & & & $(2.71)$ & $(2.20)$ & (2.36) & & & (2.53) & (2.14) \\
\hline \multirow[t]{2}{*}{ CompMom } & $0.70 * *$ & 4.22 & 0.58 & $0.73 * * *$ & $0.59 * *$ & $0.60 * *$ & 4.06 & 0.51 & $0.64 * *$ & $0.55^{*}$ \\
\hline & $(2.51)$ & & & (2.68) & (2.15) & (2.04) & & & (2.15) & (1.80) \\
\hline
\end{tabular}

The table reports performance of zero-portfolios from sorts on earnings-to-price ratio ("EP"), EBITDA-to-EV ratio ("EBEV"), EBITDA-to-price ratio ("EBP"), sales-to-EV ("SEV"), long-term momentum ("LtMom"), and intermediate momentum ("IntMom"). It also presents two meta-strategies: composite value ("CompVal") and composite momentum ("CompMom"). "St.dev." is the standard deviation of monthly returns, SR is the annualized Sharpe ratio, $\alpha \mathrm{CAPM}$ and $\alpha 4 \mathrm{~F}$ are intercepts from the countrylevel CAPM and the US stock-level four-factor model, respectively. "Gross" and "net" approaches refer to the adjustment for taxes on dividends. The means, standard deviations and intercepts are expressed in percentage terms. The numbers in brackets are $t$-statistics based on bootstrap standard errors and the significance at $10 \%$ level is given in bold characters. ${ }^{*}, * *$ and $* * *$ indicate values significantly different from 0 at 10\%, 5\% and 1\% level, respectively.

So u r c e: own study.

Table 2 depicts the mean monthly returns of the zero-portfolios in the three parts of the year: in Junuary, in December, and in the remaining months. At first sight, some interesting patterns emerge. No matter which approach we focus on - the gross or net one - the value strategies predominantly performed better in January than in the 10 following months, and subsequently even worse in December. In other words, in comparison with the rest of the year, the mean returns were on average higher in January and lower in December. For example, in the case of the composite value strategy (the gross approach), the mean monthly return in January was equal $1.50 \%$, then $0.71 \%$ on average monthly during rest of the year, and finally only $0.31 \%$ in December. In all of the observable variants of the value strategies, the Januaries outperformed Decembers. The superior performance in January relative to other months is consistent with analogous stock-level studies of value strategies (Davis 1994, Loughram 1997). Nonetheless, the Achilles heel of these observations is the fact, that in none case the January-December difference was actually significantly different 
from 0 . Although the seasonal pattern is quite vivid, it is not possible to make any formal inferences on its basis.

The behavior of the country-level anomaly seems to be completely opposite to the value effect. The impact of the turn-of-the-year phenomenon was historically totally reverse. The both examined momentum strategies had markedly higher mean returns in December than in other months, while in January they visibly underperformed. Let us focus on the composite momentum strategy in the gross approach. The average monthly in January was equal $1.93 \%$, while in December only $0.33 \%$. The remaining months delivered on average a return of $0.62 \%$. Again, similarly as in the case of the value strategies, this differences are not significant, although the observations are basically in line with similar patterns at the stock level detected for example by Yao (2012) and Novy-Marx (2012).

Table 2. Mean monthly returns on anomalies during various parts of the year

\begin{tabular}{|l|c|c|c|c|c|c|c|c|c|}
\hline \hline & EP & EBEV & EBP & SEV & CompVal & LtMom & IntMom & CompMom \\
\hline \hline \multicolumn{7}{|l|}{} & \multicolumn{7}{|c|}{ Gross returns approach } \\
\hline \hline Jan & 0.46 & 1.66 & 1.53 & 2.10 & 1.50 & 0.21 & 0.40 & 0.33 \\
\hline Other & 0.28 & 0.95 & 0.86 & 0.61 & 0.71 & 0.57 & 0.65 & 0.62 \\
\hline Dec & 0.26 & 0.32 & 0.03 & 0.50 & 0.31 & 1.81 & 2.02 & 1.93 \\
\hline Jan-Dec & 0.21 & 1.35 & 1.50 & 1.60 & 1.19 & -1.61 & -1.62 & -1.60 \\
\hline \hline Jan & $10.13)$ & $(1.05)$ & $(0.96)$ & $(1.47)$ & $(1.21)$ & $(-0.96)$ & $(-1.37)$ & $(-1.23)$ \\
\hline \hline Other & 1.14 & 0.79 & 1.22 & 1.20 & 1.11 & 0.12 & 1.18 & 0.68 \\
\hline Dec & 0.39 & 0.72 & 0.78 & 0.56 & 0.64 & 0.36 & 0.54 & 0.46 \\
\hline Jan-Dec & 0.57 & -0.30 & -0.33 & 0.05 & 0.04 & 1.60 & 2.15 & 1.89 \\
\hline \hline
\end{tabular}

The table reports mean monthly returns (expressed in percentage terms) of anomaly-based strategies in three parts of the year: Januaries ("Jan"), Decembers ("Dec"), and the remaining months ("Other"). The last row ("Jan-Dec") is the difference between returns in Januaries and Decembers. Symbols of strategies are identical as in Table 1 . The numbers in brackets are $t$-statistics.

S o u r c e : own study. 
Finally, Table 3 reports the regression parameters of the equation (1) estimated from the time series of anomaly returns. The outcome basically confirm the initial observations presented in Tables 2 .

Focusing on the gross returns, the January coefficients are always positive and range from 0.18 for EP to 1.49 for SEV. Analogously, the December coefficients are always negative and amount to from -0.03 for EP to -0.83 for EBP. The differences between January and December coefficients are historically positive for all the value strategies, nonetheless significantly different from 0 only for SEV and for the composite value strategy. The outcomes of the examinations in the net returns approach are basically similar. Equally in all the value anomalies Januaries outperformed Decembers, but the statistical significance of this observation is weak.

Table 3. Regression coefficients of seasonal dummy variables

\begin{tabular}{|c|c|c|c|c|c|c|c|c|}
\hline & EP & EBEV & EBP & SEV & CompVal & LtMom & IntMom & CompMom \\
\hline \multicolumn{9}{|c|}{ Gross returns approach } \\
\hline \multirow[t]{2}{*}{ Jan } & 0.18 & 0.71 & 0.67 & 1.49 & 0.81 & -0.36 & -0.24 & -0.29 \\
\hline & (0.19) & $(0.71)$ & $(0.70)$ & (1.65) & (1.15) & $(-0.32)$ & $(-0.23)$ & $(-0.28)$ \\
\hline \multirow[t]{2}{*}{ Dec } & -0.03 & -0.63 & -0.83 & -0.11 & -0.38 & 1.24 & 1.37 & 1.31 \\
\hline & $(-0.03)$ & $(-0.63)$ & $(-0.87)$ & $(-0.12)$ & $(-0.54)$ & (1.10) & (1.30) & $(1.29)$ \\
\hline \multirow[t]{2}{*}{ Jan-Dec } & 0.21 & 1.35 & 1.50 & 1.60 & 1.19 & -1.61 & -1.62 & -1.60 \\
\hline & $(0.22)$ & (1.35) & $(1.57)$ & (1.77) & (1.69) & $(-1.42)$ & $(-1.53)$ & $(-1.57)$ \\
\hline \multicolumn{9}{|c|}{ Net returns approach } \\
\hline \multirow[t]{2}{*}{ Jan } & 0.75 & 0.07 & 0.44 & 0.64 & 0.48 & -0.24 & 0.64 & 0.22 \\
\hline & $(0.82)$ & $(0.07)$ & $(0.41)$ & $(0.81)$ & $(0.64)$ & $(-0.21)$ & $(0.57)$ & $(0.21)$ \\
\hline \multirow[t]{2}{*}{ Dec } & 0.18 & -1.02 & -1.11 & -0.51 & -0.60 & 1.25 & 1.61 & 1.42 \\
\hline & (0.19) & $(-0.99)$ & $(-1.01)$ & $(-0.64)$ & $(-0.78)$ & (1.07) & (1.39) & (1.34) \\
\hline \multirow[t]{2}{*}{ Jan-Dec } & 0.57 & 1.09 & 1.55 & 1.15 & 1.07 & -1.49 & -0.97 & -1.21 \\
\hline & (0.61) & (1.07) & (1.42) & (1.45) & (1.42) & $(-1.30)$ & $(-0.85)$ & $(-1.15)$ \\
\hline
\end{tabular}

The table reports regression coefficients of seasonal dummies related to January ("Jan") and December ("Dec") according to the equation (1). The final row in each section presents the difference between January and December coefficients. Symbols of strategies are identical as in Table 1. The numbers in brackets are $t$-statistics based on bootstrap standard errors and the significance at $10 \%$ level is given in bold characters.

S o u r c e : own study. 
The January and December coefficients of the momentum strategies are again reverse to the value strategies, analogously to the evidence from Table 2 . The January coefficients are predominantly negative, while December coefficients highly positive, and thus their difference is also negative. Nevertheless, none of this observations is statistically significant.

\section{CONCLUDING REMARKS}

The study presents the seasonal patterns in the returns on country-level value and momentum investment strategies. During last 20 years the value strategies performed particularly well in January and underperformed in December. On the contrary, the momentum strategies had the substantially high returns in December and low in January. These observations are consistent with the explanations of the January effect related to tax selling and window dressing.

The results are mainly important for fund pickers and investment managers with a global investment mandate, who employ factor strategies. It indicates that investors should pay attention to the seasonal patterns related to the turn-of-the year effect and consider unwinding their positions in December or January, depending on which strategy they follow.

The study have three limitations of potentially high importance. First, the we do not account for transaction costs or cross-country liquidity and capital mobility constraints. Second, the sample period includes the socalled global financial crisis, that could have affected the results in some way. Third, the relatively short study period makes it impossible to draw statistically significant conclusions about the seasonal patterns in the for future long-term inter-market value and momentum returns. Nonetheless, we do not have access to any older financial data, that would enable us to test the examined strategies in years prior to 1995. Nevertheless, due to the lack of statistical significance, we are unable to formally reject the basic null hypotheses of the paper.

The future studies on the topic discussed in this paper could be pursued in a few directions. First, it would be valuable to extend the time span of the research to increase the power of the performed tests. Second, examination of also other seasonal patterns, like for example the "sell-in-May-and-go-away" effect (Bouman and Jacobsen 2002, Castro and Schabek 2014), would be beneficial for country-level investors. Finally, a careful investigation should be per- 
formed whether any other country-level strategies, e.g. related to the crosscountry size effect (Keppler and Encinosa 2011), also reveal some seasonal patterns.

\section{ACKNOWLEDGMENTS}

This paper is a part of the project no. 2014/15/D/HS4/01235 financed by the National Science Centre of Poland.

\section{UII REFERENCES}

Asness, C.S., Liew, J.M., \& Stevens, R.L. (1997). Parallels between the cross-sectional predictability of stock and country returns. Journal of Portfolio Management, 23, 79-87. http://dx.doi.org/10.3905/jpm.1997.409606.

Asness, C.S., Moskowitz, T.J., \& Pedersen, L.H. (2013). Value and momentum everywhere. Journal of Finance, 68, 929-985. http://dx.doi.org/10.1111/jofi.12021.

Balvers, R. \& Wu, Y. (2006). Momentum and mean reversion across national equity markets. Journal of Empirical Finance, 13, 24-48. http://dx.doi.org/10.1016/j.jempfin.2005.05.001.

Basu, S. (1983). The relationship between earnings yield, market value, and return for NYSE common stocks: further evidence. Journal of Financial Economics, 12, 129-156. http://dx.doi.org/10.1016/0304-405x(83)90031-4.

Bhojraj, S., \& Swaminathan, B. (2006). Macromomentum: returns predictability in international equity indices. Journal of Business, 79, 429-451. http://dx.doi. org/10.1086/497416.

Bouman, S., \& Jacobsen, B. (2002). The halloween indicator, 'sell in May and go away': another puzzle. American Economic Review, 92(5), 1618-1635. http://dx.doi. org/10.1257/000282802762024683.

Carhart, M.M. (1997). On persistence in mutual fund performance. Journal of Finance, $52,57-82$.

Castro, F.H., \& Schabek, T. (2014). 'Sell not only in May'. Seasonal effects in emerging and developed markets. Available at SSRN: http://ssrn.com/abstract=2458515 or http://dx.doi.org/10.2139/ssrn.2458515 (accessed 24.06.2015).

Chen, H., \& Singal, V. (2004). All things considered, taxes drive the January effect. Journal of Financial Research, 27(3), 351-372. http://dx.doi.org/10.1111/j.14756803.2004.00095.x.

Davis,J.(1994).Thecross-section ofrealizedstockreturns:thepre-COMPUSTAT evidence, Journal of Finance, 49, 1579-1593. http://dx.doi.org/10.1111/j.1540-6261.1994. tb04773.x. 
Fama, E.F., \& French, K.R. (2008). Dissecting anomalies. Journal of Finance, 58, 1653-1678. http://dx.doi.org/10.1111/j.1540-6261.2008.01371.x.

Haugen, R.A., \& Lakonishok, J. (1988). The incredible January effect: The stock market's unsolved mystery. Dow Jones-Irwin, Homewood, IL.

Jacobs, H. (2015). What explains the dynamics of 100 anomalies? Journal of Banking \& Finance, 57, 65-85. http://dx.doi.org/10.1016/j.jbankfin.2015.03.006.

Jegadeesh, N., \& Titman, S. (1993). Returns to buying winners and selling losers: implications for stock market efficiency. Journal of Finance, 48, 65-91. doi: http://dx.doi. org/10.1111/j.1540-6261.1993.tb04702.x.

Keppler, M., Encinosa, P. (2011). The small-country effect revisited. Journal of Investing, 20, 99-103. http://dx.doi.org/10.3905/joi.2011.20.4.099.

Kim, D. (2012). Value premium across countries. Journal of Portfolio Management, 38, 75-86.

Lakonishok, J., Shleifer, A., Thaler, R., \& Vishny, R. (1991). Window dressing by pension fund managers. American Economic Review, 81(2), 227-231. http://dx.doi. org/10.3386/w3617.

Litzenberg, R.H., \& Ramaswamy, K. (1979). The effect of personal taxes and dividends on capital asset prices: theory and empirical evidence. Journal of Financial Economics, 7, 163-195. http://dx.doi.org/10.1016/0304-405x(79)90012-6.

Loughran, T. (1997). Book-to-market across firm size, exchange, and seasonality: is there an effect? Journal of Financial and Quantitative Analysis, 30, 607-618. http:// dx.doi.org/10.2307/2331199.

Novy-Marx, R. (2012). Is momentum really momentum? Journal of Financial Economics 103, 429-453. http://dx.doi.org/10.1016/j.jbankfin.2014.10.002.

Paternoster, R., Brame, R., Mazerolle, P., \& Piquero, A. (1998). Using the correct statistical test for the equality of regression coefficients. Criminology, 36(4), 859-866. http://dx.doi.org/10.1111/j.1745-9125.1998.tb01268.x.

Rosenberg, B., Reid, K., \& Lanstein, R. (1985). Persuasive evidence of market inefficiency. Journal of Portfolio Management, 11, 9-16. http://dx.doi.org/10.3905/ jpm.1985.409007.

Rozeff, M.S., \& Kinney, W.R. (1976). Capital market seasonality: The case of stock returns. Journal of Financial Economics, 3, 379-402. http://dx.doi.org/10.1016/0304405x(76)90028-3.

Sharpe, W.F. (1964). Capital asset prices: a theory of market equilibrium under conditions of risk. Journal of Finance, 19, 425-442. http://dx.doi.org/10.2307/2977928.

Yao, Y. (2012). Momentum, contrarian, and the January seasonality. Journal of Banking and Finance 36, 2757-2769. http://dx.doi.org/10.1016/j.jbankfin.2011.12.004.

Zaremba, A. (2015a). Country selection strategies based on value, size and momentum. Investment Analyst Journal, 44(3), 171-198. http://dx.doi.org/10.1080/10293523.2 015.1060747. 
Zaremba, A. (2015b). Momentum and low-volatility effects in country-level stock market anomalies. Available at SSRN: http://ssrn.com/abstract=2621236 (accessed: 25.06. 2015).

Zaremba, A., \& Konieczka, P. (2015). Do quantitative country selection strategies really work? Available at SSRN: http://ssrn.com/abstract=2606178 or http://dx.doi. org/10.2139/ssrn.2606178 (accessed 25.06.2015). 
